\title{
Uma análise semiótica e discursiva do discurso da leitura nos manuais didáticos de língua portuguesa: um vislumbre das representações da leitura escolar
}

\author{
A SEMIOTIC AND DISCURSIVE ANALYSIS ABOUT THE READING \\ DISCOURSE IN PORTUGUESE SCHOOLBOOKS: A GLIMPSE INTO THE \\ SCHOOL READING REPRESENTATIONS
}

\section{Manuela FELICÍSSIMO *}

\begin{abstract}
Resumo: Este estudo aborda dois manuais didáticos de Língua Portuguesa para o Ensino Médio: Português: Linguagens (2003), de William R. Cereja e Thereza A. C. Magalhães, e Português: de olho no mundo do trabalho (2005), de Ernani Terra e José de Nicola. Analisamos o discurso da leitura nos referidos manuais com o intuito de apreender as representações da leitura que flutuam no imaginário escolar (via livro didático). Para isso nos valemos da análise do discurso de linha pechetiana e do instrumental metodológico da semiótica greimasiana. Neste artigo situamos nosso objeto nos estudos discursivos, apresentamos a análise e esboçamos um panorama da leitura da instituição escolar.
\end{abstract}

Palavras-chave: Representações sociais; Leitura; Análise do Discurso.

Abstract: This study approaches two Portuguese schoolbooks for what in Brazil is called "Ensino Médio": Português: Linguagens (2003), by William R. Cereja and Thereza A. C. Magalhães, and Português: de olho no mundo do trabalho (2005), by Ernani Terra and José de Nicola. We analyzed the reading discourse on these schoolbooks in order to apprehend the representations of reading that are part of the school imaginary (through the schoolbooks). To reach our goals, we resorted to the discourse analysis in Pêcheux's line and also

* Doutoranda em Letras da Universidade Federal de Minas Gerais. Professora substituta do Departamento de Letras da Universidade Federal de Ouro Preto. Contato: manuella_felicissimo@yahoo.com.br. 
to the methodological framework of the Greimas' semiotics. In this article, we consider our object to be inside the discursive researches, we present the analysis and we sketch out a view about the reading of the school institution.

Key-words: Social representations; Reading; Discourse Analysis.

\section{Introdução: situando o problema}

Este estudo se propõe a tratar do discurso da leitura. Para isso concebemos a mesma como uma atividade discursiva, ou seja, a leitura, na nossa concepção, é um ato de linguagem, é interação e, por isso, está sujeita a todas as regulações que se impõem ao discurso, tendo em vista seu contexto histórico, seu contexto institucional e interacional.

Para delimitarmos melhor nossa perspectiva de estudo para a leitura, esclarecemos que ; abordamos neste artigo a leitura escolar. Para isso selecionamos como objeto de análise dois materiais de língua portuguesa muito utilizados nas escolas públicas, Português: de olho no mundo do trabalho, de Ernani Terra e José de Nicola, e Português: linguagens, de William Roberto Cereja e Thereza Cochar Magalhães (ambos em volume único para o Ensino Médio). Como este estudo se desenvolve na perspectiva discursiva, filiado à análise do discurso e à semiótica, mais precisamente, tratamos os manuais como um lugar privilegiado para a análise do discurso da leitura neles veiculado. Nesse sentido, não entramos no mérito qualidade do livro didático (doravante LD), não objetivamos indicar ou não indicar livros, tencionamos, sim, compreender qual é e o que esse discurso fala da leitura na instituição escolar hoje.

\section{Os pressupostos teóricos: delimitando conceitos}

Nesta parte falaremos brevemente a respeito de alguns conceitos que são basilares para nossa análise e interpretação dos dados analisados. Aqui explanaremos nosso entendimento com relação às representações sociais, falaremos da perspectiva de análise de discurso que adotamos e da nossa metodologia para a abordagem do discurso no seu espaço intra e interdiscursivo. 
O arcabouço teórico é o de orientação pechetiana. Esta vertente de estudo surgiu sob o que se convencionou chamar de abordagem externalista da linguagem. Trata-se de uma disciplina que tem o claro propósito de ir além da aparência da linguagem, conforme nos explicita Maldidier et al (1994, p. 69) quando envidenciam que a linguistica do discurso se esforçava para apreender o sujeito e a situaçao de comunicação tão excluidos em virtude do postulado da imanência. Trata-se do esforço de escapar da redução da linguagem à língua, como vigorou por muito tempo nos estudos linguisticos que se restringiam aos limites da frase.

Verificamos que é propósito da AD observar a utilização da língua dentro de um quadro que considere a história, a ideologia, o papel das instituições e o aparecimento do sujeito no discurso. Concebendo o discurso como uma prática ou um conjunto de enunciados que obedecem a certas regularidades, sendo um objeto mutável e totalmente submetido às questões da história, das relações de poder e dos aparelhos ideológicos do Estado - conforme foi proposto por Pêcheux, inspirado em Althusser - a AD tenciona, no diálogo língua/historicidade cercear as condições de existência de um discurso, tal como ele é concebido.

As formações discursivas, conceito tão caro a $\mathrm{AD}$, são as regularidades do discurso que, por sua vez, se filiam às formações ideológicas (FIs). As formações discursivas nos permitem verificar o lugar de onde o discurso fala e o porquê, as formações ideológicas, por sua vez, dizem respeito a posições de classes que conflitam entre si.

Quanto à noção de ideologia, é nos pensamentos de Marx \& Engels e também por Althusser, que a AD buscou a sua compreensão para tal fenômeno na linguagem, conforme nos explica Brandão (1998, p. 22).

Em Marx e Engels temos a ideia de ideologia entendida como um instrumento de dominação que serve aos interesses da classe dominante: ideologia e alienação se confundem nessa perspectiva. Por esse viés, a ideologia foi vista como um mecanismo tanto de segregação dos homens quanto de falseamento da realidade. Fiorin (2006, p. 2829) trata desse mesmo conceito se filiando à noção desenvolvida por 
Marx e Engels. $\mathrm{O}$ autor entende que o conjunto de ideias que justifica a ordem social e a relação entre os homens é a ideologia e partilha da ideia de que essas ideias ocultam a essência dessa ordem social, constituindo-se, assim, como uma "falsa consciência".

Como nos é sabido, a ideologia constitui e também se manifesta em todas as "construções" e interações do homem. Nesse sentido, ela aparece e justifica também a linguagem. É por ter a ideologia sempre no seu horizonte de pensamento que o estudo de orientação pechetiana se torna para nós tão importante; uma vez que desejamos tratar das representações sociais da leitura, falar desse discurso a partir da contemplação do espaço intra e interdiscursivo, torna-se basilar considerarmos este conceito.

O conceito de representação social é tratado a partir do estudo de Moscovici (2003). Para o autor as representações são de natureza convencional e também prescritiva. Convencional porque elas (as representações) convencionalizam os objetos, as pessoas e também os acontecimentos.

Quanto ao aspecto prescritivo das representações, Moscovici fala da força que as representações têm sobre nós. Atuando de modo irresistível, elas penetram e influenciam toda a nossa formação e significação no mundo. Funcionando como um modelo de verdade preexistente, é possível dizer que os sujeitos re-pensam, re-citam, reapresentam (MOSCOVICI, 2003, p. 37).

Agora que já apresentamos nossa perspectiva teórica para o entendimento do discurso e das representações sociais, falaremos um pouco do tratamento que daremos ao âmbito intradiscursivo, onde utilizaremos o instrumental teórico-metodológico da semiótica greimasiana.

Teoria voltada para o estudo do texto, mais especificamente, interessada no estudo dos mecanismos de construção e aparecimento do sentido no texto, a semiótica se constitui com um arcabouço que abarca os mecanismos internos do texto, procurando por meio destes compreender como se dá o engendramento do discurso - nível mais complexo e concreto do percurso gerativo de sentido.

O nível discursivo, segundo os pressupostos da semiótica, tem sua concretude e aparecimento garantidos por meio dos temas e das figuras. Assim, a semiótica entende que há textos (discursos 
materializados) de figurativização esparsa (temáticos) e textos predominantemente figurativos, conforme nos assinala Barros (2002). Os temas e as figuras, que são modos de semiotização, garantem a passagem do nível narrativo para o nível discursivo. A tematização é concebida como a dos valores, que é abstrata, em percursos, na instância discursiva. A figurativização, por outro lado, constitui o investimento semântico, sendo por meio das figuras que ocorre a concretização dos temas. A figurativização seria fruto da construção de sentido feita pelo sujeito da enunciação.

A semiótica entende que no nível narrativo (que se concretiza no nível discursivo) ocorre o estabelecimento de um contrato entre enunciador e enunciatário; nessa relação haveria a manipulação, que pode ser entendida como um fazer persuasivo. Para isso, o enunciador lança mão de diversos procedimentos persuasivos que, uma vez interpretados pelo enunciatário, serão aceitos ou rejeitados, tendo em vista sempre o contrato proposto. $\mathrm{Na}$ análise do discurso tencionamos apreender esses procedimentos persuasivos, esse percurso tomado pelo sujeito que enuncia com o intuito de agir no outro, instaurando o efeito de verdade e também fazendo emergir os valores que giram em torno dessa verdade.

Quando examinamos as relações contratuais focamos as modalizações dos sujeitos e também dos objetos instaurados no discurso, além de atentarmos para as projeções de tempo, de espaço e de pessoa no enunciado.

Observando a relação entre enunciador e enunciatário, contemplamos o modo como o primeiro faz para que o segundo creia na verdade e nos valores impostos no contrato, ou seja, como se dá o efeito de real.

Como temos por objetivo estudar as representações da leitura, utilizaremos as categorias do nível narrativo e do nível discursivo para procedermos à análise. No nível discursivo pretendemos observar como se dá a concretização do nível narrativo na superfície do texto. Entendendo que esse "enriquecimento semântico" é responsável pelo aparecimento do discurso e que sua tessitura ocorre por meio da justaposição de temas e figuras, e, consequentemente, pela constituição dos percursos temáticos e figurativos, é nesse nível mais concreto que temos acessos às construções discursivas que nos assinalam para as 
visões de mundo construídas pelo homem quando este significa o mundo por meio da linguagem, como nos assegura Fiorin (2006).

Podemos perceber que a semiótica se apresenta como um arcabouço que permite desvendar e deslindar o texto por meio de um estudo e de um aparato conceitual e metodológico que contempla o texto, que o descreve e explicita o sentido ali pressuposto.

\section{A análise: uma leitura semiótica do discurso}

Conforme já expusemos, analisamos os livros Português: de olho no mundo do trabalho, (a partir de agora tomado como PT) de Ernani Terra e José de Nicola (volume único), $1^{a}$ edição (2005) e Português: linguagens (2003) (tratado como PL), de William Roberto Cereja e Thereza Cochar Magalhães, também em volume único e $1^{a}$ edição (2003). Dos referidos livros, analisamos as atividades de leitura, ou seja, aquelas cujo enunciado explicita essa orientação e que estão associadas a algum texto proposto para a leitura, independente do tipo e gênero textual. Nesse sentido, os exercícios foram avaliados ao longo de todo o livro. Aqui, dada a impossibilidade de reproduzir todas as atividades e todos os textos propostos para leitura (o que aumentaria sobremaneira a presente exposição), apresentaremos alguns exemplos de enunciados dessas atividades e, quando necessário, tratamos de modo breve dos textos propostos. Procuraremos focar os aspectos linguístico/discursivos identificados e não utilizaremos exemplos de atividades para ilustrar cada perspectiva analisada, faremos menção ao dado constatado e, eventualmente, colocaremos exemplos retirados dos livros. Pensamos que este critério não prejudicará a análise, pois entendemos que o conhecimento que temos de materiais didáticos (e também o leitor que pressupomos para este artigo) nos ajuda recuperar facilmente a informação dada. Contamos, portanto, com a familiaridade que temos com os manuais didáticos e com os modos de intervenção didática neles apresentados.

\subsection{Projeções enunciativas, modalidades e valores}

Quando analisamos nas atividades de leitura propostas pelos manuais selecionados (que aqui são tomados como discurso), as 
projeções de pessoa e de tempo, os valores e as modalidades, categorias propostas pela semiótica greimasiana para a apreensão dos mecanismos intradiscursivos de produção do sentido, conhecemos o modo como o enunciador se coloca no enunciado. Assim, podemos percorrer o "caminho" feito por aquele que toma a palavra e deixa, por meio da presença - ou do apagamento - de índices linguísticos, marcas de si e de seu modo de instaurar o seu enunciatário.

A primeira observação que temos a fazer é a respeito do uso constante de verbos no modo imperativo; são recorrentes orientações do tipo faça, transcreva, copie, retire, leia, etc. Estes verbos nos evidenciam uma prescrição que é orientada de um "eu” (ou "nós" = autores) para a um "você" (aluno). Temos nesses enunciados a instauração de uma obrigação, tendo em vista o fato de se tratar de um LD (algo orientado para um dever-fazer); o enunciado é essencialmente injuntivo.

Já neste aspecto é possível compreender que os enunciadores propõem, por meio de um fazer persuasivo, um contrato ao enunciatário que, por meio de um fazer interpretativo, aceita ou recusa o mesmo tendo em vista os valores ali: o saber e tudo o que implica esse saber. O enunciador pressupõe que esses valores são necessários e/ou desejados (modalizados pelo dever e/ou pelo querer-ser) ao/pelo aluno, considerando sua (do aluno) representação no cenário escolar e na sociedade. Ao apreendermos os enunciados injuntivos, ou seja, o estabelecimento de uma prescrição, temos, concomitantemente, um enunciatário colocado na posição do dever (que subsume o querer).

Foram encontradas também atividades nas quais os enunciadores se dirigiam aos seus interlocutores por meio da forma de tratamento você. Essa forma de tratamento foi por nós entendida como uma escolha linguística que evidencia o efeito de proximidade instaurado no discurso com relação às instâncias da enunciação. Paralelamente, temos evidenciada também posição superior na qual o enunciador se encontra, ele é aquele que "solicita", ele está na posição do saber, posto que ensina, ele é o que institucionalmente está autorizado a fazer, tendo em vista a ideia de autoria do livro didático. Certamente essa diferença estabelecida entre ambos confere credibilidade àquele que fala $\mathrm{e}$ também corresponde à expectativa do seu coenunciador (aluno), que institucionalmente legitima essa relação. 
Um outro aspecto que observamos foi o uso do verbo na primeira pessoa do plural (imaginemos, podemos etc.), também criando efeito de proximidade, de cumplicidade. Foi constatado o uso nós inclusivo [eu+você(s)], este nós instaura um discurso de teor didático, nele o enunciador convida o enunciatário a se juntar a ele e a tratar daquilo que é proposto, como se o processo fosse feito conjuntamente quase que num mesmo tempo de interação, seria instaurado uma espécie de simulacro da relação de sala de aula. Fica evidente o efeito de cumplicidade que ocorre dessa escolha. Não é apenas o aluno quem faz, mas tem no enunciador um "parceiro" para fazer, como uma voz que conduz e reflete junto. Como resultado temos uma amenização da relação naturalmente verticalizada que decorre do ato de ensinar. O seguinte enunciado nos exemplifica essa ocorrência: “QQ.2- Imaginemos que a ideia de Calvin dê certo e tenhamos duas gerações divididas pelo idioma. Após algumas décadas, o que aconteceria com o idioma falado pela geração mais velha? (PT, 2005, p. 16)."

No entanto, os verbos na primeira pessoal do plural não veiculam somente este efeito de sentido, o de proximidade/cumplicidade. Temos como exemplo o uso do nós misto [eu+você(s)+ele(s)], ou seja, os usuários da língua, em geral, como verificamos no exemplo abaixo:

Q.5- Nos textos argumentativos é muito comum assumirmos uma "postura de filósofos", ou seja, de indagação sobre tudo. As perguntas além de ajudarem na estruturação do texto, [...] na verdade, servem para organizar nosso pensamento, estimular nossas reflexões. (PL, 2003, p. 137)

Além desses efeitos conseguidos por meio da projeção do nós no discurso, temos também o nós exclusivo, esse nós se refere aos próprios autores + a autoridade científica: "Q.7 p Damos o nome de círculo vicioso a uma sucessão de idéias ou fatos que retomam sempre à idéia ou ao fato inicial [...] (PT, 2005, p. 84”.

Neste caso é como se o enunciador dissesse "não apenas eu digo, mas também eles", eles são a autoridade científica a qual os autores se filiam formando uma voz única. O uso da autoridade da ciência faz com que a imagem do enunciador se torne mais crível, na medida em 
que se constitui como um porta-voz dessa autoridade. Nessa forma de engajamento tem-se o efeito de verdade instaurado no discurso e, em decorrência disso, reforça-se a posição superior do enunciador e a inferior do enunciatário, que aqui aparece de forma mais explícita na posição do não saber.

Para além da marca de pessoa no discurso, encontramos a busca do efeito de impessoalidade. Nestes casos apreende-se o apagamento da instância que fala. Certamente trata-se de um efeito no discurso, uma vez que instância enunciadora está pressuposta na própria existência do enunciado. Vejamos o exemplo: "Q.5-Em três passagens, a autora utilizou parênteses para melhor organizar o texto. Qual a função das sequências entre parênteses? (PT, 2005, p. 99)". Neste exemplo não há marcas linguísticas que evidenciem a voz do enunciador. Temos o discurso em terceira pessoa, ou seja, uma debreagem actancial enunciva, conforme os pressupostos da semiótica. Reforçamos, trata-se de um efeito de sentido, já que os enunciadores estão pressupostos no enunciado e inclusive na própria instauração da pergunta.

Além das projeções de pessoa, outros recursos são empregados pelos enunciadores-autores na construção do seu fazer-persuasivodiscursivo. Um aspecto interessante de se observar é o uso de recursos imagéticos em PL, muito abundante com relação a PT.

PL é um livro rico em imagens, especialmente fotografias, além disso, traz seções denominadas como "Fique ligado! Pesquise” e Intervalo. Constatamos que os autores reconhecem e apelam para a identidade jovem, uma identidade espetacular (afinada com as imagens) e que tem uma linguagem que lhe é peculiar. Essa identidade reconhecida e legitimada funciona como um recurso persuasivo que corrobora com a aceitação por parte do enunciatário do contrato em questão (o da aquisição do saber).

É interessante observar que esse processo persuasivo ocorre por meio do despertar de desejos e sentimentos, etc. Esse aluno presente nos enunciados e nas atividades como um todo (que é aparentemente a projeção de uma imagem que o aluno deseja ser, haja vista sua própria representação no livro) permite-nos observar a modalidade do quererser, na sua função passional. É dessa modalidade que, segundo Barros (2002, p. 63), decorrem as paixões simples, como desejo, anseio, avidez, curiosidade, entre outras. O não-querer-ser, por outro lado, está 
relacionado às paixões da repulsa, do medo, da aversão, do desinteresse. Notamos que o efeito passional contribui para a aceitação do contrato instaurado no discurso em questão e aparece pautado em valores deônticos (institucionais), estéticos (aquilo que é bom e que também é belo), que favorecem o pressuposto querer do aluno-leitor e, com isso, levá-lo a fazer.

No que diz respeito às projeções de tempo, podemos identificar, em ambos os livros, o largo uso do presente gnômico ou omnitemporal, em que o momento de referência é um sempre implícito (FIORIN, 2005a). Por meio desse recurso são construídas as "verdades eternas" - ou que se pretendem como tais - da ciência, da religião, da sabedoria popular: "Q.2 O texto oral tem características muito particulares - as chamadas marcas de oralidade. Aponte, na primeira fala da Graúna, exemplos da oralidade. (PT, 2005, p. 24)”. O presente gnômico confere ao enunciado o efeito de sentido de verdade, uma verdade eterna, atemporal. O fazer-saber parece se constituir muito por meio dessa marca temporal. Este tipo de enunciado carrega geralmente um efeito de "genericidade", assim como os provérbios, na perspectiva de Kleiber (2000). Esse efeito é conseguido porque recupera as formas “já ditas” e, por meio dessa recuperação da memória, que são enunciações prévias, instaura um tom de verdade cristalizada.

O presente do indicativo aparece simulando o momento da enunciação (reforçado por advérbios como aqui e agora). Associado a ele aparece, muitas vezes, o pretérito perfeito $1 .{ }^{1}$ Essas projeções servem para organizar temporalmente o discurso e criam um efeito de progressão, muito coerente, aliás, com os propósitos do livro didático.

Encontramos nas atividades também o futuro do pretérito, ocorrendo de modo a atenuar o tom do enunciado, instaurando a ideia de hipótese, probabilidade: "Seria possível compreender exatamente o que Calvin quis dizer com "você não acha isso muito fiambre? É lubrificado! Bem eu vou na fase". Por quê? (PT, 2005, p. 16)"

${ }^{1}$ Fiorin (2005a) distingue o pretérito perfeito 1 (anterioridade em relação ao agora) e o pretérito perfeito 2 (concomitância a um marco temporal pretérito), a que se associa o pretérito imperfeito, com seu valor durativo, inacabado. 
Em linhas gerais, constatamos que as projeções de tempo não estão relacionadas apenas ao aspecto temporal do discurso, mas também ao modo de dizer, modalizando muitas vezes o dito, como ocorre no uso do futuro do pretérito. O uso do presente do indicativo, por exemplo, não apenas nos situa no momento da enunciação (presente pontual), como se associa, com frequência, ao presente gnômico, ajudando a construir o efeito de sentido de verdade daquilo que é dito (o discurso autorizado da ciência).

Por fim, temos a modalização pelo ser. Esta confere existência ao objeto: Ao dizer que algo é de determinado modo, os enunciadores fazem o aluno saber da existência desse objeto e do modo de sua existência. É o que podemos perceber nos fragmentos abaixo. "Q.3As conjunções são palavras que se prestam a estabelecer relações lógicas entre os segmentos textuais. Nos trechos abaixo, indique o tipo de relação estabelecida pelas conjunções destacadas [...]. (PT, 2005, p. 89)".

Percebe-se que esse recurso se esteia muito no uso do presente gnômico, os enunciadores fazem o "objeto" existir para o aluno e, ao mesmo tempo, mostram que ele é assim, que não pode ser de outro jeito. Institui-se assim uma voz de "natural", "normal" (e não "normativa") e que, por isso mesmo, é tomada como verdade.

Quanto aos valores presentes nas atividades de leitura dos livros analisados, considerando que se trata de um discurso de cunho predominantemente prescritivo, pudemos observar a predominância de valores éticos, ligados à correção da leitura. Sob diversas "facetas", os enunciadores-autores privilegiam estes valores: seja quando evitam os termos "certo" e "errado", substituindo-os por "desvios" ou por "incoerências"; seja quando tratam da questão da adequação (o que remete também ao seu contrário: o inadequado e/ou aquilo que deve ser evitado); seja, enfim, quando propõem atividades de reescrita (em geral, de acordo com os ditames da variedade padrão, como se ela fosse a melhor ou a mais correta). Esses procedimentos, focados na correção, também apontam para uma possibilidade de leitura, legitimando-a e, ao mesmo tempo, excluindo outras que não se mostram à luz da inteligibilidade. Além disso, encontramos também os valores estéticos, em PL, ligados à beleza e à afetividade.

No quadro a seguir apresentamos uma síntese esquematizada dos aspectos predominantes que apreendemos no discurso sobre a leitura dos LDs em foco: 
Quadro 1 - Organização das categorias de tempo, espaço e pessoa e modalização do discurso

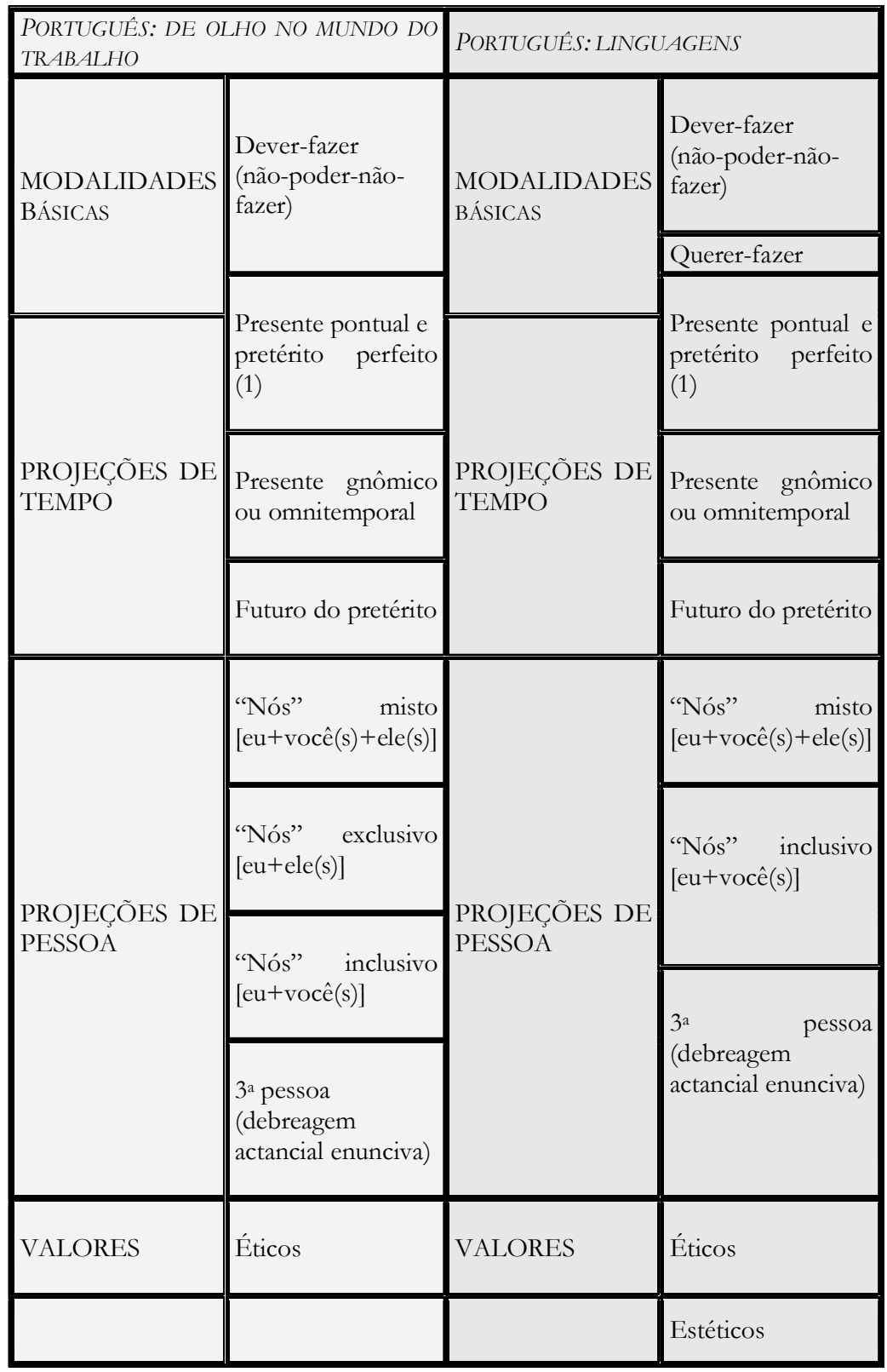


2.2 Percursos temáticos e formações discursivas: a materialização das representações no discurso

Passemos agora à identificação e análise dos percursos temáticos a fim de identificarmos as filiações desses percursos em determinadas formações discursivas.

Segundo Fiorin (2005b) os temas e as figuras materializam-se nas FDs (formações discursivas). Podemos entender que a recorrência de certos temas no discurso da leitura corresponde aos modos como a concebemos e a fazemos existir, neste caso, na escola. O discurso em questão é predominantemente temático, de figurativização esparsa, como propõe Barros (2002). Os temas e as figuras são modos de semiotização do mundo e exprimem, de acordo com Fiorin (2005b) nossas visões de mundo. Algo que nos permite acreditar que, vislumbrando este aspecto, vislumbramos as representações da leitura, verificamos o modo como a nomeamos, como a legitimamos e a tornamos verdadeira na realidade escolar.

Ao tratar dos temas, consideramos aqueles que aparecem explicitamente nos enunciados e também os mesmos implícitos podem ser recuperados nas entrelinhas. Para elencarmos os temas, consideramos, também, aqueles veiculados nos textos propostos, pois eles são aquilo que é propostos/selecionado para ser lido.

Identificamos na análise do discurso em questão o percurso temático da linguística, que aparece filiado a FD acadêmico-científica. Este percurso foi apreendido quando verificamos temas e/ou figuras que remetem ao discurso da ciência, a linguística especialmente. Há atividades, em PT, por exemplo, que fazem referência ao estudioso Jean Michel Adam, além do aparecimento de nomes como Jean Dubois, Ingedore Vilaça Koch etc., também encontrados na análise desse material.

A referência a nomes e ou conceitos da linguística nos permite identificar a formação do referido percurso que, pensamos, aparece com a finalidade conferir credibilidade àquele que diz, promovendo, portanto um fazer-crer por meio da legitimidade que o discurso científico funda. Convém observar que os enunciadores realizam esse fazer-crer tendo em vista não somente a imagem do aluno, mas, provavelmente, da equipe de avaliadores do livro. Por meio desse procedimento 
argumentativo, aquele que fala evidencia que não apenas sabe fažersaber, como também demonstra que sabe. Reforça essa tese o fato de os nomes e/ou títulos que eventualmente são referendados pouco dizerem ao alunado. Assim, o percurso temático da linguística cumpre pelo menos três funções: confere autoridade à fala do enunciador, constitui o ethos de autoridade dos mesmo e instaura o caráter de verdade ao dito.

Ancorado ao percurso temático da linguística, encontramos o (sub)percurso da temático da linguagem. Este percurso é identificado nas reflexões a respeito da linguagem que os manuais contemplam, são as chamadas atividades de cunho epilinguístico. Consideramos a ocorrência desse (sub)percurso quando apreendemos conceitos da linguística que contribuem para o estudo da linguagem: gênero, condições de produção do discurso, adequação da linguagem, por exemplo. Além de termos da perspectiva de diversas áreas de estudo da linguística, como polifonia, variação linguística, semântica, etc.

Neste trabalho defendemos a ideia de que a presença do percurso temático da Linguística e do (sub)percurso da linguagem nos assinala o movimento de ruptura pelo qual o ensino de língua portuguesa passou, em especial após da década de 1980. A inserção dessa perspectiva de estudo de língua evidencia a voz do discurso acadêmico que promoveu uma nova perspectiva para a disciplina língua portuguesa.

Encontramos no quadro deste discurso de ruptura também o discurso da tradição, que nos foi mostrado por meio do percurso temático da gramática normativa, também presente no discurso em análise. Acreditamos que a recorrência de questões de gramática nos exercícios de leitura pode ser entendida quando recuperamos a imagem do professor, aquele que escolhe entre os livros didáticos aprovados o manual com o qual deseja trabalhar. É sabido que muitos professores - e não somente eles, mas também grande parte da sociedade - creditam o ensino de língua portuguesa ao ensino de gramática. A presença da gramática neste caso se constitui como um saber comum entre o enunciador-autor e o professor. Esse saber partilhado, geralmente, é fundamental no momento da escolha do livro didático pelo professor. Contribui para esta afirmação a evidente 
constância de certos livros/autores na escolha pelos professores dos livros aprovados e na rejeição de materiais muito bem avaliados e, no entanto, pouquíssimo solicitados, justamente por se afastarem do convencional, pensamos nós.

A outra possível razão para a recorrência do discurso da gramática nas atividades de leitura é a própria constituição do saber Língua Portuguesa. As atividades são propostas no âmbito dessa disciplina e por isso tendem privilegiar os aspectos constituintes desse saber. A gramática ainda é tida como o dorso da disciplina Língua Portuguesa.

Esse conhecimento gramatical está associado ao "bem" conhecer - para bem poder utilizar - a língua portuguesa. Lara (2004), em seu estudo sobre o imaginário de língua portuguesa segundo aqueles que a ensinam, observou que não apenas os professores que ensinam Língua Portuguesa, como também as pessoas pouco escolarizadas, entendem que a língua portuguesa legítima é aquela que se constitui como norma culta, a variedade de prestígio atrelada à gramática normativa.

Também Barros (1999), ao analisar o próprio discurso da gramática, verifica que se trata de um discurso prescritivo, que impõe uma normatividade e que instaura os limites de aceitação dessa norma. A língua portuguesa aparece cerceada por valores da ordem do estético (beleza e elegância, por exemplo), aos valores afetivos (devemos amar a língua) e aos valores éticos (que instauram a dicotomia certo/errado), valorizando certos usos e proibindo outros.

Verificamos que, tanto professores (sujeitos que ensinam a língua, quanto o próprio objeto considerado o manual de correção da língua e também guardador da mesma, ambos filiados à disciplina língua portuguesa e constituintes da identidade da mesma, legitimam o discurso da gramática, da norma, da correção. Esses valores aparecem no discurso em questão, como apontamos nos enunciados.

O percurso temático do vestibular, que envolve tanto questões de vestibular quanto questões sobre vestibular também foi constatado. Há seções inteiras dos livros dedicadas às questões retiradas de vestibulares, assim como há atividades que tratam de determinados conteúdos tendo em vista a adequação ao vestibular de certas instituições. Como no seguinte exercício: 
Q.2- Um aluno acostumado a decorebas e a reproduzir textualmente aquilo que lhe foi ensinado se enquadra no perfil desejado pela Unicamp? [...] Que situações devem ser evitadas para que você não tenha sua redação anulada? (P'T, 2005, p. 149).

No nosso entender, o percurso temático do vestibular está associado ao percurso temático de preparação para o mercado de trabalho. Ambos nos permitem verificar a imagem da leitura como algo utilitário, funcional, extremamente pragmático, que corresponde, aliás, à guinada que o ensino de língua portuguesa sofreu, em especial a partir da década de 1980, quando atende em massa a uma clientela que vinha de classes menos favorecidas e que tinha na escola o expoente da oportunidade de trabalho. Esse percurso foi apreendido também quando verificamos a recorrência de gêneros de prestígio social que não se restringem ao domínio literário (por exemplo, a notícia, o anúncio, a carta, o editorial, o artigo científico) e que são considerados, segundo os próprios PCNs, necessários para a plena participação do sujeito na sociedade em que vive e por oferecerem ao sujeito melhores possibilidades de acesso ao trabalho (BRASIL, 2000, p. 64-65).

Com relação ao diálogo que estabelecemos entre o percurso temático de preparação para o mercado do trabalho com o percurso temático do vestibular, o fazemos por entender que, em nossa sociedade, o vestibular é um pré-requisito para uma formação superior, formação essa que confere uma profissão, possibilitando a inserção no mercado de trabalho.

Além disso, relembramos a presença de valores éticos, que são da ordem do inteligível (que remetem àquilo que é útil e/ou correto).

Q.6- Apresentamos, a seguir, um parágrafo de um texto com falhas de articulação, escrito por um vestibulando. Leia-o e, em seguida, reescreva-o, estabelecendo a articulação necessária entre palavras, frases e idéias. Adapte o que for necessário. (PL, 2003, p. 451).

Outro percurso evidenciado foi o percurso temático éticocidadão, apreendido por meio da identificação de temas como 
filosofia, sociedade, jornalismo, política, relacionamento, cinema, etc. Aqui verificamos um processo de constituição da ética-cidadã inerente à prática de leitura. Para esse percurso contribuem também os chamados "temas transversais". Este aparece quando encontramos nos textos temáticas como ética, pluralidade cultural, meio ambiente, saúde, orientação sexual, trabalho e consumo (BRASIL, 2000, p. 40), necessárias à formação cidadã do aluno. Vejamos a seguinte atividade:

Q.2- Segundo o texto, que conseqüências decorreram da mudança na legislação ambiental? (PT, 2005, p. 47).

O percurso temático do saber (envolvendo linguagem e metalinguagem) instaura domínio do saber ler e se articula ao percurso temático da tradição literária escolar, que se constrói a partir de nomes como Machado de Assis, Ítalo Calvino, Millôr Fernandes, Castro Alves, Moacyr Scliar, entre outros, que constituem referências legítimas no contexto escolar e também propiciam a chamada "identidade linguística escolar".

Por fim, especialmente em PL, encontramos o percurso temático da juventude, constituído no entroncamento de temas como cinema, sexo, música, gírias, rock, etc. Esse percurso contribui para a constituição da identidade jovem que se instaura no livro, como já afirmamos.

\subsection{O interdiscurso}

A identificação dos percursos temáticos nos permitiu vislumbrar as seguintes formações discursivas: a da tradição escolar (percurso temático da gramática normativa, percurso temático do saber, percurso temático do vestibular e percurso temático da tradição literária), a formação acadêmico-científica (percurso temático da linguística e (sub)percurso temático da linguagem), a formação discursiva sóciopolítica (percurso temático ético-cidadão, percurso temático de preparação para o mercado de trabalho, percurso temático da juventude).

Cada uma dessas formações discursivas nos falam de lugares sócio-históricos que legitimam o discurso da leitura no contexto em 
questão. Assim, verificamos linguisticamente a perspectiva social, utilitária, política, linguística e também tradicional que constitui a leitura. Fica evidente o valor pragmático que ela (a leitura) tem na escola (via livro didático) e os valores em torno desse saber. A legitimação desse saber encontra respaldo nas FDs que elencamos (e também em outras que provavelmente existem, mas que não abordamos) e nos permitem verificar o modo como concebemos e representamos esta prática leitura. Esse modo de semiotizar a leitura, funcional e utilitário, responde ao discurso da democratização do ensino que abriu as portas da escola para o aluno de classes menos favorecidas. Os valores da ordem do inteligível evidenciam o controle da prática de leitura; há um modo próprio de ler e, além disso, no processo de seleção de textos e temáticas para serem lidas, notamos que há objetos próprios para serem lidos. Essa seleção e também a exclusão que lhe é inerente nos deixam compreender os procedimentos de controle que o discurso da leitura sofre e que também impõe. Nesse processo ouvimos falar a voz da ideologia dominante, que prescreve os modos de ler e o que deve ser lido, tendo em vista uma pretensa homogeneização do saber e também a voz das camadas menos favorecidas que, legitimando o discurso em questão e os valores em torno desse discurso, desejam se conjuntar com ele, por meio da aceitação do contrato.

Quando verificamos as vozes da cientificidade, além dos procedimentos de correção, que aparecem nas categorias de tempo, presente gnômico, por exemplo, no uso do nós exclusivo e no percurso temático da linguística, podemos compreender como se dá a formação do efeito de "única voz". Por meio desse recurso, segundo Barros (2002, p. 151) "abafam-se os percursos em conflito, perde-se a ambigüidade da múltipla posição, toma-se uma única direção".

Felicíssimo (2009) retoma Bakhtin e fala da aparência monologal do discurso. A autora tenta explicar que este discurso, por meio da aparência que lhe é conferida, se torna guardião da "verdade" e promove um anseio dos sujeitos inseridos em determinada prática discursiva de se "apoderarem" desse discurso. Tornando-se um "discursoreferência", esse discurso de "voz única" e verdadeira difunde certos princípios ideológicos (que o legitimam) e fazem os sujeitos desejarem deles se apoderar. 
Essa voz de verdade que encontra amparo nas FDs de que tratamos, torna o discurso da leitura algo crível, quase que incontestável, atuando na constituição do saber, da mentalidade dos sujeitos escolares e também da sociedade, haja vista o diálogo escola/sociedade.

\section{Conclusão}

O que percebemos na análise procedida não nos foi algo diferente do que já sabíamos por meio de muitos outros estudos já desenvolvidos a respeito da leitura. Acreditamos que nossa contribuição está no fato de termos apresentado linguisticamente, por meio das categorias que se materializam no discurso, o retrato desse interdiscurso que conhecemos. O lugar das regulações, do conflito ideológico e de classes, o lugar dos valores, da historicidade e da memória do discurso. O discurso da leitura nos mostrou tanto as vozes das políticas públicas para escola (FD sociopolítica), quanto as vozes do social, através do discurso da cidadania, assim como também se fez presente a reminiscência do discurso da disciplina língua portuguesa, por meio da gramática normativa e também do movimento de ruptura com as abordagens linguísticas mais recentes. Falar desses discursos e apontálos linguisticamente foi o nosso maior objeto. Assim, conseguimos tratar das representações (imaginários) e mostrá-la. O imaginário da correção, do utilitarismo, da cientificidade, por exemplo.

Este estudo não cerca, de forma alguma, as perspectivas de análise do discurso da leitura. No entanto, pensamos que contribuímos com um olhar diferente sobre o livro didático (não qualificativo, mas discursivo) e sobre a leitura, procurando entender como ela é concebida e significada, tendo em vista os condicionamentos enunciativos que investigamos.

\section{Referências}

BARROS, D. L. P. Conceitos e imagens da norma no português falado no Brasil: o discurso da gramática. São Paulo: USP, 1999. (Relatório parcial de projeto de pesquisa). 
Teoria do discurso: fundamentos semióticos. 3. ed. São Paulo: Humanitas/FFLCH/USP, 2002.

BOURDIEU, P. Questões de sociologia. Rio de Janeiro: Marco Zero, 1983.

BRANDÃO, H. M. B. Introdução à análise do discurso. 7. Ed. rev. Campinas: Ed.UNICAMP, 1998.

BRASIL. Secretaria de Educação do Ensino Médio. Parâmetros Curriculares Nacionais do Ensino Médio.Brasilia: MEC/SEF, 2000.

FELICÍSSIMO, M. Representações da leitura em manuais didáticos de língua portuguesa. 2009. 141f. Dissertação (Mestrado em Estudos Linguísticos) - Universidade Federal de Minas Gerais, Belo Horizonte.

FIORIN, J. L. Três questões sobre a relação entre expressão e conteúdo. Itinerários, Araraquara, n. especial, p. 77-89, 2003.

. Dos princípios teóricos. In: As astúcias da enunciação: as categorias de pessoa, espaço e tempo. 2. ed. São Paulo: Ática, 2005a. p. 27-58.

. Linguagem e ideologia. 8. ed. São Paulo: Ática, 2005b.

Introdução ao pensamento de Bakhtin. São Paulo: Ática, 2006.

FREITAG, B.; MOTTA, V. R.; COSTA, W. F. da. O livro didático em questão. São Paulo: Cortez; Autores Associados, 1989.

LARA, G. M. O que dizem da língua os que ensinam a língua: uma análise semiótica do discurso do professor de Português. Campo Grande: Ed. UFMS, 2004.

MALDIDIER, D. Discurso e ideologia: bases para uma pesquisa. In: ORLANDI, E. P. (Org.). Gestos de leitura: da história no discurso. Campinas: Ed. UNICAMP, 1994. p. 67-102. 
MOSCOVICI, S. Representações sociais: investigações em psicologia social. 4. ed. Petrópolis: Vozes, 2003.

PÊCHEUX, M. Análise automática do discurso. In: GADET; F; HAK, T. (Orgs.). Por uma análise automática do discurso - uma introdução à obra de Michel Pêcheux. Campinas: Ed. UNICAMP, 1990. p. 61-105. 